\title{
Disorientation and self-consciousness: a phenomenological inquiry
}

\author{
Pablo Fernández Velasco ${ }^{1,2,3}$ (iD
}

Published online: 30 January 2020

(C) The Author(s) 2020

\begin{abstract}
The present paper explores the phenomenology of disorientation and its relationship with self-consciousness. Section 1 discusses previous literature on the links between self-location and self-consciousness and proposes a distinction between minimal selflocation (which requires only an ego-centric frame of reference) and integrated selflocation (which requires the integration of egocentric and allocentric frames of reference). The double aim of the paper is to use this distinction to deepen our understanding of spatial disorientation, and to use the phenomenology of disorientation to elucidate the role that integrated self-location plays in shaping self-consciousness. Section 2 starts by looking at the experience of being "turned around", which is a common experience of disorientation. This analysis leads to the conclusion that integrated selflocation is transmodal and depends on all three egocentric axes, and that disorientation destabilizes this integrated self-location. Section 3 explores a corpus of reports of disorientation episodes and highlights four key characteristics of these experiences (anxiety, vulnerability, confusion and diminishment) and their links to self-consciousness, focusing on the transformations in both the lived body and the experience of space. The central thesis of this paper is that during disorientation a destabilization of integrated self-location results in a diminished form of self-consciousness.
\end{abstract}

Keywords Disorientation · Spatial cognition · Phenomenology $\cdot$ Self-location $\cdot$ Selfconsciousness

Pablo Fernández Velasco

p.fernandezvelasco@gmail.com

1 Département d'études cognitives, Institut Jean Nicod, ENS, EHESS, CNRS, PSL University, Paris, France

2 Spatial Cognition Lab, Department of Experimental Psychology, University College London, WC1E 6BT, London, UK

3 Department of Philosophy, University College London, WC1E 6BT, London, UK 


\section{Self-location and self-consciousness}

As I write, my laptop is in front of me, my chair below me, the window to my left, and beyond that, is the city. All of these elements are arranged spatially in my perception, in relation to each other and also in relation to myself, so that I can always locate myself with respect to them. If walking one day without paying much attention I arrived at a familiar square but from an unexpected angle, I might become disoriented. I would still be able to say that I am in such and such square, and the pavement, the road and the surrounding street lights would still be spatially arranged around me in my perception. Nevertheless, something would have gone awry in my self-location, and there would be a sense in which I don't fully know where I am. This diminishment in my self-location will in turn change how I experience the space around me, and even how I experience myself within said space. In the present paper, I will use the relationship between selflocation and self-consciousness as a framework to explore the phenomenology of disorientation and use this phenomenological analysis to in turn clarify said relationship.

Much of the discussion on the relation between orientation and self-consciousness has revolved around the issue of self-location. In his book Varieties of Reference, Gareth Evans argues that self-location is a necessary element of self-consciousness, not just due to the spatiality of the world surrounding the subject, but due to the subject itself being a spatial entity within this world (Evans 1982). Evans has in mind a somehow intellectualised notion of self-consciousness that implies the subject grasping a simple theory explaining how the world results in her perceptions of the world. Jose Bermudez extrapolates Evans' general idea and brings it to bear on a primitive, nonconceptual notion of self-consciousness. This re-conception emphasizes the active rather than the passive side of self-location:

A vital element in a self-conscious subject's grasp of how he himself is a part of the physical world is indeed derived from an understanding of how his perceptions are a function of his location in precisely the way that Evans brings out. But it must not be forgotten that a vital role in this is played by the subject's own actions and movement. Appreciating the spatiality of the environment and one's place in it is largely a function of grasping one's possibilities for action within that environment.

-p.223, Bermudez 1998.

In a recent paper, Adrian Alsmith reviews the philosophical literature on self-location and draws a distinction between perspectival and agential accounts of self-location (Alsmith 2017). Perspectival accounts hold that if an experience is perspectivally structured, then it is self-locating (for proponents, see Evans 1982, Cassam 1997 and Schwenkler 2014). In contrast, agentive accounts hold that an experience is selflocating if it represents an object as the focus of its subject's possible action. Alsmith highlights Bill Brewer (1992) and Susana Schellenberg (2007) as two major proponents of agentive accounts of self-location. Alsmith himself presents several arguments in favour of agentive accounts of self-location (and against perspectival accounts of selflocation). 
A central issue with perspectival accounts of self-location, argues Alsmith, is that there is a critical difference between locating perspectives and locating subjects. Different perceptual systems representing space locate the origin of perception as different single points in space (e.g. the eyes in the case of visual perception and the ears in the case of auditory perception). Thus, it would follow from perspectival accounts of self-location that subjects are multiply located, while subjects seem to self-locate in a unitary way. Christopher Peacock makes a similar point when he says that "a point of view in space cannot be the producer" of an action (p. 133, Peacocke 2019).

According to Alsmith, while perspectival accounts fail to account for the unitary character of self-location, agentive accounts of self-location are well-equipped to deal with this problem:

The issue is easily resolved by properly appreciating the significance of the fact that the object is represented as the focus of the subject's possible action. To represent an object in this way is not to represent it in relation to a single position from which one perceives and acts. Rather it is to represent it in relation to a single, unified thing from which one perceives and with which one acts.

-p.278, Alsmith 2017.

In this paper, I will follow an agentive understanding of self-location (and of selfconsciousness). The motivation for this is double. On the one hand, I am fairly convinced by the arguments that Alsmith and others bring forth. On the other, agentive accounts are much more useful when it comes to clarifying the phenomenology of disorientation and the way in which self-location shapes self-consciousness.

Before diving into the phenomenology of disorientation, it is important to discuss a point of disagreement between Brewer and Schellenberg, two of the major proponents of agentive accounts of self-location. The disagreement concerns the role that egocentric (self-referenced) and allocentric (world-referenced) frames of refence play in selflocation. Egocentric reference frames are coded in relation to the subject's body, position and orientation. Allocentric refence frames are coded independently of the subject, based on cues, geometrical features or cardinal directions (Klatzky 1998). While Brewer's focus is on a primitive perceptual egocentricity that represents perceptual objects in spatial relation to the subject, which he claims doesn't require a system of allocentric representations (Brewer 1992), Schellenberg thinks that self-location requires the subject moving from egocentric to allocentric frames of reference. ${ }^{1}$ In particular, it requires what she deems entertaining alter-ego points of view on the object. An alter-ego point of view is an engaged allocentric frame of refence, engaged

\footnotetext{
${ }^{1}$ In some of his recent work, Bermudez defends the view that allocentric frames of reference are necessary to be conceptually self-conscious, but that only egocentric frames of reference are necessary to be nonconceptually self-conscious: "To be non-conceptually self-conscious is to be in receipt of and be able to act upon, locally self-specifying information - that is, information about one's immediate bodily disposition and about one's spatial relation to the local environment. Nonconceptual self-consciousness is paradigmatically underpinned by somatic proprioception and by the outward-directed senses. Conceptual self-consciousness brings a degree of emancipation from that perception-dependence. It allows the thinker to act and form plans in ways that are not bound either by the present time or by the present location" (p.113, Bermúdez 2017). In what follows, I simply hope to show that allocentric frames of reference are not necessary for self-location, without delving into the distinction between conceptual and non-conceptual self-consciousness.
} 
in the sense that it is "the focal point of a potential egocentric frame of reference" (p. 463, Schellenberg 2007).

There are two objections that I would like to raise against Schellenberg's view. The first one is that all allocentric frames of reference are focal points of potential egocentric frames of reference, because there is a linearly transformable relationship between egocentric and allocentric coordinates (Ekstrom, Huffman and Starrett 2017). A viable alternative is to understand the distinction between engaged and disengaged allocentric frames of reference as a distinction between online and offline systems of spatial representation. To understand this online-offline distinction, we have to look at the disorientation studies of Wang and Spelke and of Waller and Hodgson.

Wang and Spelke trained subjects to learn the array of objects in a room and then point to unseen targets. They compared the performance of oriented and disoriented (through self-rotation) subjects and found that disorientation impaired both the subject's relative accuracy in pointing to different objects and their absolute accuracy in pointing to all objects (Wang and Spelke 2000). Waller and Hodgson then extended the above experimental design by asking subjects to judge the relative directions between different objects in the room (e.g. "imagine that you are at the door, facing the couch, point to the TV") and found that disorientation actually increases inter-object pointing accuracy, supporting the idea that disorientation elicits a switch from an online system of spatial representation to an offline system of spatial representation (Waller and Hodgson 2006). While the offline system produces enduring and stable spatial representations of the environment, the online system produces representations that are transient and dynamically updated through spatial perception, which makes the online system relatively more precise (i.e. less coarse) than the offline system, but unstable and unprecise during disorientation. According to Waller and Hodgson, if the online representation system was active, it was harder for the subjects to focus on a task (inter-object spatial relations) that required only an offline spatial representation. Thus, the task was easier for disoriented individuals that were operating based solely on an offline system of spatial representation, resulting in their increased performance. To go back to the discussion of Schellenberg's notion of engaged allocentric frames of reference, we should clarify that in normal circumstances, the online system of spatial representation integrates both allocentric and egocentric frames of reference in a dynamic way. In this sense, one can say that the relevant allocentric frames of reference are engaged as long as the online system of spatial representation is active.

My second, more substantial objection to Schellenberg's view is that it is unclear that an allocentric frame of reference is actually necessary for self-location. Take patient $\mathrm{CF}$, who has an impairment locating objects relative to their environment but not relative to the perceived viewpoint. Burgess and colleagues ran a series of tests on patient CF that suggest "the presence of a selective deficit of allocentric spatial memory" (p.246, Burgess et al. 2006), that is, a deficit in using allocentric frames of reference. Importantly, patient CF showed no impediment in using egocentric frames of reference. This impairment in using allocentric frames of reference resulted in severe navigational impediments, but her performance on a broad range of different tests, including space perception tests, was flawless. Patient CF showed "spared recognition of landmarks, object locations and spatial scenes from the same point of view, and unimpaired spatial abilities such as mental rotation" (p.248, Burgess et al. 2006). 
I raise the case of patient $\mathrm{CF}$ case not necessarily as an objection against the core of Schellenberg's agential account of self-location, but only against the role that allocentric frames of reference play in arguing for that account. At heart, what Schellenberg's account seems to require is not that the subject knows precisely how the environment would look from a different location, but just that she has the capacity to entertain the possibility of re-locating. ${ }^{2}$ An allocentric frame of reference might be needed for the subject to know what an environment might look like from a different viewpoint, but it is not needed for the subject to tacitly know that moving within this environment will result in a new viewpoint and that she has the capacity necessary to bring about this movement. While patient CF doesn't have the knowledge of what an environment might look like from a different viewpoint, she still has the tacit knowledge required for spatial perception.

Following this line of thought, it seems that while egocentric frames of reference might be necessary for self-consciousness, allocentric frames of reference are definitely not. This points to a difference between two notions of self-location, which I will term minimal self-location and integrated self-location. Minimal self-location involves only egocentric frames of reference. Integrated self-location, on the other hand, involves the integration of egocentric and allocentric frames of reference through the online system of spatial representation. Integrated self-location is the norm in everyday human activity, and it underpins our standard navigational abilities. When this capacity for integrated self-location is compromised during disorientation, disoriented individuals can still orient in a minimal sense (extreme cases like immersion in sensory deprivation tanks being a possible exception outside the scope of this paper). The same is true of patients with navigational impairments such as $\mathrm{CF}$, who can still perceive the spatial arrangement of objects around her and act accordingly. Similarly, a disoriented individual that cannot properly navigate within her environment, is still able to perceive that a given door is to her left, and she can walk to that door or reach out to grab a cup of coffee on the table to her right, because she is still able to self-locate minimally.

Here, I will remain neutral on the question of whether or not minimal self-location is required for self-consciousness. ${ }^{3}$ My claim at this point is a negative one: integrated self-location (which is the standard case of self-location in non-pathological cases) is not necessary for self-consciousness. A large part of the philosophical discussion of self-consciousness revolves around the capacity for first-person thought, but even if we grant that there is a form of self-consciousness in experience that grounds the capacity to entertain first-person thought, the study of first-person thought does not exhaust the study of self-consciousness. My focus in this paper will not be on what forms selfconsciousness are necessary for first-person thought or on what capacities might be required for self-consciousness. Rather, I am interested in exploring some of the "different forms of non-conceptual self-consciousness that are both logically and

\footnotetext{
${ }^{2}$ After all, what Schellenberg defends as the core of her thesis on spatial perception is that what makes perception possible are not action tokens but the capacity to act, so that "perceiving intrinsic spatial properties requires perceiving objects as perceivable from locations other than the one that one happens to occupy" (p. 661, Schellenberg 2007). In a similar way, what makes self-location possible is not tokens of mental relocation (i.e. engaged allocentric frames of reference), but the capacity to re-locate.

${ }^{3}$ The widely held view that (minimal, following my distinction) self-location is necessary for selfconsciousness is not without its opponents. Raphaël Millière appeals to the case of a deafblind individual (MVS) to defend that self-location is not necessary for self-consciousness (Millière 2019)
} 
ontogenetically more primitive than the higher forms of self-consciousness that are more usually the focus of philosophical debate" (p. 294, Bermúdez 1998) or, in other words, the different forms of the pre-reflexive self-consciousness that renders reflexive self-consciousness possible (p. 9, Sartre 1956). In particular, I am interested in the form of self-consciousness that is characteristic of our ordinary oriented experience of the world and in how this form of self-consciousness is transformed during episodes of spatial disorientation. Consequently, one of the central aims of this paper is to investigate the role that integrated self-location plays in shaping our everyday self-consciousness, even if, as I have just argued, self-consciousness can occur without integrated self-location.

In what follows, I will use the distinction between minimal and integrated selflocation to assist in a phenomenological investigation of spatial disorientation. In return, this investigation will shed light on the role that integrated self-location play in self-consciousness.

\section{Disorientation along the three egocentric axes}

"Suppose you were in some place that you know perfectly well, such as your study, or the street in which you live; suppose that you shut your eyes for a second, and that in this short interval the external world about you turns round to the extent of two right angles on a vertical axis passing through your body, so that an object previously in front of you should be behind you, another placed on your right hand should have shifted to your left, and so on; suppose that in this rotation the external world should be displaced as a whole, and that the objects, notwithstanding their change of position in regard to you, should retain exactly their relations to one another; lastly, suppose that during this strange revolution you have not moved, but that, on the contrary, you have the firm conviction that you have been absolutely at rest. Now open your eyes and look around you, and fancy the feeling of bewilderment that would seize you, and you will have an idea of the impression I experienced when I was under the attack of what is called vertigo of direction".

-report in p. 156, Binet 1885.

The feeling of being turned around was first mentioned in the context of a discussion on instinct started by Charles Darwin in the journal Nature (see Schmidt di Friedberg 2018 for a review) and was first explored methodically in Alfred Binet's articles Vertigo of Direction and Reverse Illusions of Orientation (Binet 1885, 1894). Binet's work is built primarily on reports from subjects who had been turned around, a state that Binet initially termed vertigo of direction. ${ }^{4}$ Subjects report an illusion of orientation, sometimes even characterised as a type of hallucination, which is usually accompanied by distress and anxiety. The illusion carries the impression that the space around the subject is aligned in the opposite direction than it should, so that it seems to the subjects as if they have been unknowingly turned around. One subject reports:

\footnotetext{
${ }^{4}$ The sense in which being "turned around" is similar to vertigo is that during both experiences the world around one appears to hover and only "clicks back into place" when the feeling recedes. However, as Binet himself concedes in his later work, the term "vertigo of direction" is inexact and rather misleading. Therefore, I will not be using this term in the present paper.
} 
"My confusion was extreme, and I found myself for some time in a state of complete disorientation, and unable to comprehend the situation. [...] All the objects and streets occupy positions exactly opposite to those which they should".

-report in p. 340, Binet 1894.

As one of the subjects emphasizes, being turned around is very different to finding oneself lost in an unknown place or visiting a new environment:

"Here you know very well where you are. You have a very clear sense of direction and you know perfectly where things ought to be; only this direction and this place are just the opposite of their real position. The station of Mont Parnassus ought to be on the right, and I did not understand why I did not see it there".

-report in p. 340 , ibid.

Being turned around is quite a common occurrence. As for myself, I often get turned around when I come out of a metro station and I take the exit on the wrong side of the street by mistake, so that what I expect to find before me appears behind me and vice versa. In these cases, once I figure out my mistake, the illusion fades away, as if the environment had again turned in the right direction. Subjects are often bewildered or perplexed after being turned around, and sometimes they are even unable to recognise familiar environments, as in the following case:

Instead of taking the right to return to the Place de la Republique, I took the left toward the Hotel de Ville... While on my way I felt sure of meeting the Place de la Republique. Thus my confusion was extreme on coming to the Hôtel de Ville... I was some moments in recognizing it. Then I recognized the Hôtel de Ville, without destroying the illusion. It disappeared, however, very quickly... when I understood the cause of my mistake.

-report in p. 341 , ibid.

Following the discussion in the previous section, the inference to the best explanation is that underlying the phenomenon of being turned around is a misalignment of the subject's allocentric and egocentric frames of reference, caused by errors in the online system of spatial representation and resulting in a degraded integrated self-location. The exact cause of the errors is outside of the scope of this paper and it might vary on a case by case basis. In some cases, it is the subject's misguided conscious inferences or navigational decisions that result in a mistaken integration. In others, it might be due to an accumulation of error in sub-processes that contribute to the online system of spatial representation (e.g. path integration) or the result of biases in these sub-processes.

There are at least four aspects of the experience of being turned around that are worth discussing in the context of self-location and self-consciousness: 1) it is associated with feelings of distress and anxiety; 2) it causes perplexity, unfamiliarity and often prevents recognition of well-known environments; 3) egocentric frames of reference 
are not affected by it; and lastly, 4) the allocentric frames of reference are almost always misaligned $180^{\circ}$. We will go back to the associated feelings that come with disorientation experiences (not solely those of being turned around) in section 3, and in this section, we will discuss the three remaining aspects.

The failure in environment recognition and the perdurance of egocentric frames of reference are best understood if studied together. Let us take the case of one of Binet's subjects who declares that the landscape appeared as if it had turned itself around. Clearly, what he means is not that he saw the environment around him literally turning or that instead of seeing what was in front of his torso he was seeing what was behind the back of his head. And in the case of the subject who unexpectedly comes upon Hôtel de Ville, he sees the building, but he cannot recognise it. The sense in which the landscape "turns around" (or analogously, the sense in which the subject gets turned around within the landscape) is that objects are in the opposite direction of where they are expected to be based on an allocentric frame of reference that is off by $180^{\circ}$. Hence the perplexity and the bewilderment. Nevertheless, an egocentric frame of reference remains, and this suffices to maintain correct minimal self-location. That is, the turned around subject is still able to indirectly locate herself with respect to objects present in her visual field. She perceives that a sycamore tree is to her right, that some children are shouting somewhere behind her or that such and such a building are there, at a given distance from her body and at given angle from the direction she is facing. Binet's subject still sees a big building in front of him, he is only unable to identify that building as Hôtel de Ville, because of the misalignment between his allocentric and egocentric frames of reference. Importantly, in this case it is not that the integrated selflocation vanishes, so that only minimal self-location remains (as in the case of patient $\mathrm{CF})$. The integrated self-location is still there, only in a more uncertain form and associated with the illusory feeling of being turned around.

What being turned around reveals is that even if we granted that only egocentric frames of reference are required for minimal self-location and thus for self-consciousness, allocentric frames of reference still play an important role in shaping selfconsciousness. For instance, allocentric frames of reference support recognition, which is made evident by the occasional failure in recognising familiar environments after being turned around. And even in those cases in which the turned around subject recognises the places around her (e.g. I recognise station Montparnasse, which is to my right, but it feels like it should be to my left) a feeling of unfamiliarity usually emerges that changes how the environment is perceived and how the subject feels towards that unfamiliar environment. Finally, a turned around subject self-locates minimally with respect to such and such a building (e.g. Hôtel de Ville), but fails to self-locate with respect to a global environment (e.g. Paris), and as we will see in section 3, this has a substantial effect on her self-consciousness.

The question remains why the allocentric and egocentric frames of reference should be misaligned by precisely $180^{\circ}$, as it happens in the majority of the reported cases of being turned around. Here, it is necessary to introduce the three axes of egocentric space: frontward-backward, left-right and up-down. According to John Campbell, what characterises these axes is that the subject uses them immediately for action by exploiting ways in which humans are not symmetrical: "If we were symmetrical, being double-jointed and able to look either way, then our current notions of in front and behind simply could not be applied to ourselves, could not guide our actions in the way 
that they do." (p.15, Campbell 1995). While it is easy to see how this applies to the frontward-backward axis, it becomes harder when it comes to the other two axes. As Campbell himself points out, up-down has an immediate relevance for action but is better characterised as dependent on the gravitational field rather than on the longitudinal axis of the body, and there is no notable left-right asymmetry that could be employed for action in the way that Campbell suggests. Nevertheless, something that makes the left-right distinction paramount is the role it plays in spatial orientation. This is a point that Immanuel Kant illustrated quite well in his 1768 essay "What Does it Mean to Orient Oneself in Thinking":

In the proper meaning of the word, to orient oneself means to use a given direction (when we divide the horizon into four of them) in order to find the others - literally, to find the sunrise. Now if I see the sun in the sky and know it is now midday, then I know how to find south, west, north, and east. For this, however, I also need the feeling of a difference in my own subject, namely, the difference between my right and left hands. I call this a feeling because these two sides outwardly display no designatable difference in intuition. If I did not have this faculty of distinguishing, without the need of any difference in the objects, between moving from left to right and right to left and moving in the opposite direction and there by determining a priori a difference in the position of the objects, then in describing a circle I would not know whether west was right or left of the southernmost point of the horizon, or whether I should complete the circle by moving north and east and thus back to south. Thus, even with all the objective data of the sky, I orient myself geographically only through a subjective ground of differentiation.

-p.7-8, Kant 1786.

This subjective ground of differentiation between left and right is given ostensibly in a non-conceptual form (De Monticelli 1986). However, the left-right axis is necessary but not sufficient for the kind of orientation that Kant has in mind - in a three-dimensional space, three egocentric axes are required. This becomes clearer when we reconsider the case in terms of integrated self-location. What Kant is describing is integrating an allocentric frame of reference (the four cardinal directions) with an egocentric frame of reference based on a single cardinal direction that is present in both (i.e. the sun at noon). When we are facing the north, west is to our left, east is to our right and south is backwards. However, this requires that we face north, and that we do so without being unknowingly upside down. If we were in a space in which we couldn't tell whether we were upside down or not (e.g. a zero-gravity space that was symmetrical along the vertical axis), knowing that we are facing north would permit us to locate south (which would be behind us), but not to locate east and west. Conversely, if we were not able to differentiate backward from forward, we would be in a similar position to a creature unable to tell left from right through a subjective ground of differentiation. The reason that this latter point is often overlooked is that while the left-right distinction requires a subjective ground of differentiation (and one that we need to learn and that humans lack in early infancy), as Campbell indicates, the difference between backward and forward is given through the asymmetry of our own body along the forward-backward axis. 
The idea that the left-right axis (unlike the up-down and forward-backward axes) does not play a significant role in driving action is also supported by work in the distribution of defensive peripersonal space (DPPS). Animals respond to stimulus more strongly when the stimulus takes place in close proximity to the body, within the DPPS region (Graziano and Cooke 2005). A recent study mapped the face's DPPS and found asymmetries in its geometry: the face's DPPS is projected forward (as opposed to backward) and upward (Bufacchi and Iannetti 2016). In line with Campbell's view, while the forward-backward asymmetry depends on the bodily frontward-backward axis (so that if the subject lies down the DPPS is still larger before the subject's head than behind it), the up-down asymmetry depends on gravity and not on the subject's body (so that if the subject lies down, looking up or looking sideways, the DPPS becomes larger towards the ceiling, not towards the "top" of the subject's longitudinal axis). The reason to bring this topic into our discussion is that the experimenters found no left-right asymmetry in the geometry of DPPS, which supports the idea that while the up-down and frontward-backward axes have immediate relevance for action, this is not the case for the left-right axis. ${ }^{5}$ If this is correct, then it seems that the primary role of the left-right axis is integrated self-location, which would not be possible without this axis.

That all three egocentric axes are necessary for integrated self-location gains further support when we discover that illusions of orientation do not happen only along the frontward-backward axis, but also along the left-right axis and even along the up-down axis. Flournoy, in his work Des Phénomènes de Synopsie, describes a left-right axis inversion while waking in the dark at night:

We clearly know that we are lying in bed with the right side toward the wall, and in spite of that we feel that we have the wall to the left and the room to the right and are flustered at the tenacity of this illusion, which can resist reasoning for many seconds; unless, extending the arms, the contact with the wall causes it to vanish suddenly and brings the mental images back into place.

-p.188, Flournoy 1893, my translation.

The difficulty here is that most of our allocentric frames of reference are already oriented along both the frontward-backward and the left-right axis, so that a $180^{\circ}$ misalignment implies a misalignment with respect to both axes. Flournoy's description could be taken as a left-right inversion or as a $180^{\circ}$ reversal. A better example would be the following thought experiment: Imagine a familiar rectangular room in your office that has no windows and a single door in the middle of one of its walls. One night, as a prank, some co-workers change the spatial arrangement of the objects within the room in a mirror-way with respect to an axis of symmetry drawn perpendicularly from the door. Now imagine that you enter the room unaware of the change. The objects that you would expect to your right would be to your left and vice versa, producing a left-right inversion illusion. The same effect could be achieved using a virtual reality environment. For the sake of argument (and to avoid switching the furniture in rooms to

\footnotetext{
${ }^{5}$ A further review of studies about different peripersonal spaces (i.e. not only DPPS) does not report any geometric asymmetry along the left-right axis either (Bufacchi and Iannetti 2018).
} 
surprise my colleagues and see what happens), I will take Flournoy's anecdote as a case of left-right inversion.

Something that I find specially interesting about Flournoy's report is that, as it happens in darkness, the illusion is not primarily visual. This is also the case in the $180^{\circ}$ reversals mentioned earlier, but what the darkness element in Flournoy's story makes particularly noticeable is that the experience of integrated self-location is transmodal. Flournoy feels that the wall is to his left, but the wall is nowhere to be seen on either his left or his right. The wall is expected to be on his left based on the (erroneous) integration of allocentric and egocentric frames of reference and this integrated selflocation generates the expectation that were he to turn on the light, he would see the wall to his left and that were he to reach to his left he would touch the wall. Finding the wall to his right, consequently, makes the illusion vanish. The transmodality of integrated self-location means that it has an influence on both our perception (as we saw in Binet's reported cases of non-recognition and unfamiliarity) and our experienced possibilities for action (e.g. reaching to the left to touch the wall).

It seems that if cases of left-right inversion are hard to find (we need darkness, thought experiments or virtual reality), cases of upside-down reversal would simply not exist. For how could one not know if one is upside-down or not? Not only is our world clearly different along the vertical axis, with furniture and carpets on the ground and lamps on the ceiling, but gravity always tells us where down is. Even if someone had stuck furniture to the ceiling as a prank, we wouldn't be fooled. We would simply feel that the furniture is upside down, without undergoing any subsequent illusion. Luckily for us, up-down reversals exist in micro-gravity settings, as reported by Skylab (Cooper 1976; Johnston and Dietlein 1977) and Spacelab astronauts (Oman et al. 1986; Oman 1987, 1990):

Two of the most common situations were when working upside down (relative to their normal $1-\mathrm{G}$ orientation in training), or when floating right side up but viewing another crewmember floating upside down in the cabin. In either case, crew often experienced the striking illusion that the surrounding walls, ceiling, and floors had somehow exchanged identities. In the first situation, whichever surface was closest to their feet seemed like a generic floor. Surfaces approximately parallel to their body now seemed like walls, and overhead surfaces were perceived as ceilings. In the second situation, the orientation of the inverted crewmember determined the direction to the "floor" ... Areas of Skylab that had locally incongruent visual vertical cues also triggered VRIs [Visual Reorientation Illusions].

-p. 211-212, Oman 2007.

These illusions of orientation along the up-down axis show similar characteristics associated to being turned around illusions such as perplexity, lack of recognition, unfamiliarity and distress. However, as one could have expected, the effects of updown axis illusions are much stronger, often provoking nausea and even vomiting for the astronauts.

Together, the illusions along the three egocentric axes point to the role of the body in integrated self-location, in line with Husserl's notion of the body as the zero point ("Null Punkt") of orientation (Husserl 2012a): 
The body, for Husserl, not only has an orientation in space, it also orients space around it...Every space is experienced from the inescapable 'here' of my body: right and left, up and down, near and far. All orientation involves a body and all distances are marked off taking the body as the point of departure.

-p.450, Moran and Cohen 2012.

And as we saw earlier, for the body to work as the zero point of orientation all three axis are needed, and one of these axes (up-down) depends on gravity, not on the body itself. It is only given the up-down axis delineated by gravity that the body becomes the meeting point of the left-right and frontwards-backwards axes and orients space around itself. While the agentive accounts of self-location introduced in section 1 highlight the role of the body in minimal self-location as the necessary origin of one's capacity to act, Husserl's "Null Punkt" highlights the role of the body in integrated self-location as the necessary origin of the left-right and frontward-backward axes that connect egocentric and allocentric frames of reference.

In this section, we have seen that illusions of orientation can happen along the three egocentric axes, supporting the idea that all three egocentric axes are involved in generating an integrated self-location. While the up-down and the frontwardbackward axes also play an immediate role for action, the primary function of the left-right axis seems to be the alignment of allocentric and egocentric frames of reference. The effects of different illusions of orientation also reveal that integrated self-location is transmodal and therefore has an effect on both our perception (e.g. influencing recognition) and our experienced possibilities for action. Finally, we have started to bring to the foreground some of the feelings often associated with disorientation (such as perplexity, unfamiliarity and distress), which will be explored more indepth in the next section.

\section{The phenomenology of disorientation}

The "bell-tower of Marcellinara" has become the symbol of this form of existential anguish and sense of disorientation. De Martino, in La fine del mondo, recounts an experience of his own in 1950s' Calabria, when he and a friend stopped in the village of Marcellinara to enquire for directions from an elderly shepherd. To preclude any possibility of error, De Martino asked the shepherd to accompany them as far as the turning that they needed to take a few kilometres ahead:

"He got into the car somewhat reluctantly, as though he feared some kind of trap, and this reluctance gradually grew into distress, because from the car window, out of which he was constantly peering, he had lost sight of the bell-tower of Marcellinara, the point of reference for his extremely circumscribed domestic space. Due to the disappearance of the bell-tower, the poor old man felt 
completely disoriented: and only with difficulty did we manage to get him to the right turning and to obtain the information that we needed." (De Martino, 1977, pp. 480-481)

At last they brought the shepherd back to the village. By now he was in a state of great anxiety, and, in his impatience to see the bell-tower reappear, travelled with his head leaning out of the car window: "When he finally saw it, his face relaxed and his aged heart began to quieten, as though he had won back a 'lost homeland" (ibid., 1977, pp. 480-481).

-p. 6, Marcella Schmidt di Friedberg 2018

The anxiety described in the "bell-tower of Marcellinara" scenario is common to many episodes of disorientation, although of course this anxiety can occur with different degrees of intensity. My team and I have been collecting reports of disorientation episodes in order to build a corpus of experiences of disorientation that can help us characterize the phenomenon, in the style in which Binet used subjective reports to characterize the experience of "being turned around". The existing reports collected so far in this corpus give us some very valuable information about disorientation experiences.

Some of the episodes of disorientation reported are illusions along the three egocentric axes (mostly along the frontward-backward axis, although there is one case of an up-down inversion while scuba diving), but these are not the majority. There are cases that involve exploring new environments (e.g. New York subway), cases in which not remembering well what one expected to be a familiar environment prompts disorientation ("In a mall, I disoriented myself trying to find a specific store. I had a vague memory of the place and walked in that direction. I started to feel disoriented when I didn't remember the stores I was seeing"), and cases in which subjects are unable to interpret a map (e.g. the Tokyo Subway map) or in which their GPS stops working ("I was in New York City, and I was trying to figure out if I should walk to the left or to the right after exiting a restaurant. The mobile GPS was not calibrating, and so no matter the direction I walked in, the GPS pointed to the opposite direction").

One of the main benefits of the corpus is that it reveals a series of feelings that are often reported in relation with disorientation and that can help us understand the phenomenon:

- anxiety ("I didn't know where I was heading nor to which side of the station I was going. The feeling is horrible and stressful"; "I was anxious really anxious because I didn't want to be late to my first class")

- vulnerability or helplessness ("it made me feel vulnerable"; "I felt unsafe and anxious because no one was with me, and the environment was not familiar to me"; "I just felt confused and helpless — I didn't know what to do")

- confusion or perplexity ("I was slightly confused, as all of the streets seemed similar and we kept walking in a circle although we took different turns") 
- diminishment or isolation ("I get nervous the longer it takes me to figure out the direction. I attempt to find out which street/avenue I am at. It feels like I am a tiny spec in all this action that's happening around me"; "Feeling of being left alone, feeling of not being able to make decisions and unable to be independent.").

This is in line with the feelings that subjects report in Binet's corpus. Furthermore, $66 \%$ of subjects agreed (from somewhat agree to strongly agree in a Likert scale) that the experience of disorientation made the environment feel unfamiliar, although no subject in our survey explicitly reported lack of recognition of the kind that Binet's subjects occasionally talk about. It might well be that lack of recognition is mainly due to misalignments along an egocentric axis, as this is an effect that astronauts also report experiencing when they undergo an up-down inversion illusion. Something that our corpus makes particularly clear is the presence of feelings of vulnerability, helplessness and diminishment or isolation that emerge in relation with disorientation. These feelings are particularly worth reflecting on in the context of self-consciousness. In what follows, I will pursue a phenomenological analysis in an effort to better understand the vulnerability, helplessness, diminishment or isolation that often arrive when experiencing disorientation. ${ }^{6}$

One of the ways in which anxiety manifests during disorientation is through pressure on one's chest - a restriction that goes hand in hand with the sense of diminishment that many subjects report. ${ }^{7}$ Here, it is illuminating to look at Thomas Fuchs's work on the phenomenology of depression for an example of the connection between anxiety and diminishment. During depression there is a diffuse anxiety and an overall bodily rigidity, so that "the external aims and objects, as it were, withdraw from the patient; they are not at the disposal of his body as a matter of course ... All this means that the body's space shrinks to the nearest environment" (p. 110, Fuchs 2005). When talking about the body's space, Fuchs is referring to the body as the medium of our embodied experience of being-in-the-world, the lived-body. Fuchs' characterisation of anxiety in depression is similar to Heidegger's view that "in anxiety, what is environmentally ready-at-hand sinks away" (p.232, Heidegger 1962). The idea of body-space reduction (hereon BSR) is very fruitful for understanding the phenomenology of disorientation, and it resonates with the subjective reports of disorientation experiences and the oftreported feelings of diminishment, vulnerability and helplessness (e.g. "it feels like I am a tiny spec in all this action that's happening around me"). The point is not that these three feelings can be equated to a single feeling (namely, the BSR that is characteristic of anxiety) or even that they must necessarily occur together, but simply that all of these feelings are strongly associated and integrated together during most disorientation experiences, and that this association is well-captured with the concept of BSR.

Something that Binet's subjects are careful to point out is that the anxiety comes as a result of the disorientation and does not precede it. The same can be said of the feeling of unfamiliarity - it is not the cause but the result of the disorientation. This leaves us

\footnotetext{
${ }^{6}$ Like most people, when disoriented, I usually get anxious and quickly try to reorient myself. However, I have recently developed a practice of reflecting on the experience whenever I naturally happen to become disoriented (i.e. without intently looking for said experiences through psychogeographical drifting or similar methods). This series of phenomenological exercises inform to a great extent the following discussion.

${ }^{7}$ As Fuchs points out, anxiety comes from the Latin "angustiae" which means "narrows", "restriction" (Fuchs 2005).
} 
with the question of what is it in the disorientation experience that brings about both the unfamiliarity and the anxiety (i.e. BSR). After all, anxiety and unfamiliarity alone do not constitute disorientation, and there is something that makes the experience of disorientation unique and different from other experiences involving unfamiliarity or anxiety - different from depression for instance. I have already claimed that during disorientation there is a degradation in the subject's integrated self-location, but more needs to be said about how this degradation appears in the phenomenology of disorientation itself if we want to understand the connection between disorientation and selfconsciousness.

Charles Oman compares the micro-gravity VRIs that were discussed in the previous section with figure-ground illusions: "VRIs typically occur spontaneously, but as with figure ground illusions, onset depends on visual attention and is therefore under cognitive control. One astronaut commented: 'If you really want a surface to be "down", you can just look at it and decide that it is"” (p. 213, Oman 2007). This kind of cognitive control can also be exerted in left-right inversions in darkness like the one described by M. Flournoy, and I have noticed myself that even during experiences of being "turned around", how I allocate my attention influences the persistence or extinction of the illusion, so that I can just let the illusion be or I can make a concentrated effort to mentally rotate my allocentric frame of reference and extinguish the illusion.

What the analogy between illusions of orientation and figure-ground illusions reveals is that just as there is a perceptual instability in figure-ground illusions, there is a different type of instability when it comes to disorientation. During disorientation, the online system of spatial representation fails to integrate egocentric and allocentric frames of reference satisfactorily and this brings about a destabilization in integrated self-location. The way that this transmodal destabilization appears in experience is through an increase in uncertainty of what lies beyond one's egocentric space. When I become disoriented, it becomes uncertain whether behind a row of buildings is a given part of the city or another. It is as if the rest of the city were hovering behind my field of vision, undecided about its position - in some cases it even feels like the city is no longer there behind the buildings. Another Husserlian concept, "the horizon of experience", can help us understand how this destabilization in integrated self-location results in BSR and unfamiliarity:

Everything that genuinely appears is an appearing thing only by virtue of being intertwined and permeated with an intentional empty horizon, that is, by virtue of being surrounded by a halo of emptiness with respect to appearance. It is an emptiness that is not a nothingness, but an emptiness to be filled out; it is a determinable indeterminacy.

-p.41, Husserl 2012b.

The idea is that every experience happens within a framework of references that carries a given set of possibilities, and that this framework is incorporated in the experience itself. The allocentric frames of reference present in integrated self-location would be part of this horizon of experience, carrying with them a set of possibilities, just as the allocentric representation of having the wall to the left in the dark room of Flounoy's 
story carried with it a set of possibilities for action (reaching to his left and touching the wall) and for perception (turning on the light and finding the wall to his left). To get an intuitive grasp of the concept of the horizon of experience (particularly in terms of spatial allocentric frames of reference), a simple phenomenological scenario should suffice: While you are in a familiar room, your office for instance, you only see the elements that are directly around you — such as a chair or the door-, but you feel the location of a set of invisible spatial objects - such as the corridor, the main entrance of the building, and some local landmarks surrounding you - that are hovering somewhere out of sight, framing your experience of the space in which you find yourself. These out-of-sight elements are part of your horizon of experience.

The horizon of experience is a determinable indeterminancy, which means that it can be determined with varying levels of (un)certainty. The destabilization in integrated self-location that occurs during disorientation is a destabilization of the horizon of experience, which becomes more uncertain as a result. In his later work, Husserl distinguishes the horizons of well-known worlds (homeworld or "Heimwelt") from those of strange or alien worlds ("Fremdwelt"), so that there are familiar and unfamiliar horizons of experience (Husserl 1970). By destabilizing the horizon of experience, disorientation turns the subject's world unfamiliar. As we saw earlier in the case of nonrecognition after being turned around, an allocentric frame of reference that is part of integrated self-location contributes to perception. Therefore, a phenomenal "homeworld" that has undergone destabilization in integrated self-location will become unfamiliar or strange in lack of this frame of reference — the subject will no longer be at home in the world. ${ }^{8}$

Because the horizon of experience carries with it a given set of possibilities, a destabilization of that horizon results in an destabilisation in the experienced possibilities of the subject, so that the possibilities for action become less salient, more ambiguous or simply disappear. A subject that after being turned around doesn't recognise Hôtel de Ville, for example, perceives that the building in front of him can be entered (just like any other building), but not that the inside of Hôtel de Ville can be reached by entering that building — this is not a possibility that lies in his horizon of experience, and no more is the possibility of going around the building and reaching the Seine open to the disoriented subject. Furthermore, he knows that the building in front of him can be entered, but not that he himself can enter it. It is not only that he cannot know whether or not the building in question is open to the public, but that in the strange world in which he now finds himself, he is no longer "welcome" to explore unfamiliar buildings - the perceived possibility of entering unknown buildings has become weakened as a result of the disorientation. The destabilization that occurs during disorientation shrinks the subject's possibility space, and this underlies the diminishment, vulnerability and helplessness associated with BSR.

\footnotetext{
${ }^{8}$ Here, "being at home in the world" simply refers to a subject who is in her homeworld (Heimwelt) as opposed to an alien world (Fremdwelt). Although this is similar to the use of the term in discussions of Heidegger's work and although Heidegger himself claims that anxiety is a form of being not-at-home (p. 233, Heidegger 1962), I would not want to frame the discussion in Heideggerian terms. The reason for this is that whether or not the subject can ever be at home in the world in the Heideggerian sense is an open discussion. Dreyfus defends in Hedegger's view, "Dasein is unheimlich [unsettled], that is, never truly at home in the world" (p.45, Dreyfus 1991), which means that for Heidegger, there is no state of "being at home in the world" that disorientation could destabilise.
} 
The above analysis gives us all of the elements that we need in order to see the effect that disorientation has on self-consciousness: the subject undergoes a reduction of its body-space and of its possibility space within an unfamiliar environment framed by an uncertain horizon of experience. Equally important, seeing the effect that disorientation has on self-consciousness allows us to see the effect that typical integrated self-location has on self-consciousness: integrated self-location enriches self-consciousness by contributing to the horizon of experience, providing the subject with a set of possibilities for both action and perception.

Importantly, disorientation is a degradation in self-location (conceived agentively), and as such, a degradation in self-consciousness (conceived agentively ${ }^{9}$ ), but outside of maybe extreme cases (e.g. prolonged episodes of nearly total darkness leading to de-realisation), disorientation does not result in an obliteration of self-consciousness. Borrowing the wording from the discussion of orientation in the work of Erwin Straus (Straus was discussing orientation in dancing), disorientation transforms "the structures of immediate experience" in which self-consciousness is embedded (p. 30, Straus 1966).

Here, when we think of self-consciousness, we have to remind ourselves that, as Bermudez points out, grasping one's possibilities for action within an environment plays a fundamental role in self-location and therefore, in the "self-conscious subject's grasp of how he himself is a part of the physical world" (p.223, Bermúdez 1998). Going back to the agential accounts of self-location explored in section 1, just like minimal self-location contributes to self-consciousness by supporting our capacity to act within an egocentric frame of reference, by supporting our capacity to act within an engaged allocentric frame of reference, integrated self-location contributes to the fullbodied self-consciousness and to the elaborate sense of self that we experience when we are at home in the world.

\section{Conclusion and future directions}

After reviewing existing discussions on the ties between self-location and self-consciousness, I drew a distinction early on between minimal self-location (involving only egocentric frames of reference) and integrated self-location (involving egocentric and allocentric frames of reference). This distinction gave me the necessary framework to explore the phenomenology of disorientation, starting with experiences of being turned around, then studying illusions of orientation along the other two egocentric axes and finally experiences of disorientation that did not necessarily involve illusions along the egocentric axes. I proceeded to show that illusions of orientation can happen along the three egocentric axes, supporting the idea that all three egocentric axes are necessary for integrated self-location. I then argued that integrated self-location is transmodal, having effects on both perception and perceived possibilities for action. In section three, a phenomenological investigation of the feelings associated with disorientation (in particular, BSR and unfamiliarity) led me to the conclusion that during disorientation the subject undergoes a reduction of its body-space and of its possibility space within an unfamiliar environment framed by an uncertain horizon of

\footnotetext{
${ }^{9}$ For an early account of agentive self-consciousness see Husserl's notion of "Ich kahn” ( $\$ 38$ of Husserl 1990 and $\S 28$ of Husserl 1970). According to Husserl, the subject experiences the world through her lived body as a series of "I can's", that is, as a series of possibilities for action.
} 
experience. I concluded by using this phenomenological analysis to bear on to the distinction between minimal and integrated self-consciousness, arguing that although integrated selflocation is not necessary for self-consciousness, it contributes to the richer form of selfconsciousness that is characteristic of our everyday experience.

The reduction of body-space and possibility space during disorientation suggests that there might be empirically-testable links between disorientation and the sense of agency, and between disorientation and peripersonal space. Another potential avenue of research is to study the connection between the different neural mechanisms of spatial cognition and the destabilization of integrated self-location. For instance, in vivo recordings demonstrate that without vision the rodent head direction system (a system of cells within the hippocampal formation that discharge as a function of the directional heading of an animal) becomes unstable very quickly (Cheung et al. 2012). It would be interesting to explore if and how the instability of the head direction system relates to the instability of the horizon of experience characteristic of episodes of disorientation.

In this paper, I have focused on what one could deem paradigmatic disorientation experiences, involving feelings of anxiety, confusion, vulnerability and unfamiliarity. However, not all experiences of disorientation follow the same pattern. In her book Geographies of Disorientation, Marcella Schmidt di Friedberg draws a distinction between what she calls the uncanny feeling of getting lost (negative aspects of disorientation experiences) and the delicious flavour of getting lost (positive aspects of disorientation experiences): "from being an "uncanny" experience and a "real tragedy", getting lost may alternatively be loaded with expectations, the desire for change, and the longing for novel encounters and explorations" (p.8, Schmidt di Friedberg 2017). In the corpus I am establishing with my team, a small subset of the subjects report experiencing positive feelings when disoriented ("the prospect of being totally lost is sometimes good fun," "[I felt] joy... it was very cool and [I had] never felt something like that"), sometimes even experienced in conjunction with negative feelings such as fear or confusion. A research question worth exploring is how the phenomenology of negative and positive aspects of disorientation experiences differ and in what aspects they are similar. I suspect that the degradation of integrated self-location that underlies negative aspects of disorientation experiences also underlies positive aspects disorientation experiences, but more work needs to be done to investigate under which circumstances the destabilisation of the horizon of experience brings about not a strange and unfamiliar world, but a novel world full of freedom and possibility.

"The question is how to get lost. Never to get lost is not to live, not to know how to get lost brings you to destruction, and somewhere in the terra incognita in between lies a life of discovery".

-p.1, Solnit 2005

Acknowledgements I would like to thank Rory Madden, James Laing, Roberto Casati, Hugo Spiers, the Spatial Cognition Lab at UCL and the attendants of the 2019 Annual Conference of the British Society for Phenomenology for their helpful comments and advice. I am also grateful to Andreas Falck and Brent Strickland for their help with setting up the online questionnaire. I would also like to thank two anonymous reviewers for their insight and their literature suggestions. 
Open Access This article is licensed under a Creative Commons Attribution 4.0 International License, which permits use, sharing, adaptation, distribution and reproduction in any medium or format, as long as you give appropriate credit to the original author(s) and the source, provide a link to the Creative Commons licence, and indicate if changes were made. The images or other third party material in this article are included in the article's Creative Commons licence, unless indicated otherwise in a credit line to the material. If material is not included in the article's Creative Commons licence and your intended use is not permitted by statutory regulation or exceeds the permitted use, you will need to obtain permission directly from the copyright holder. To view a copy of this licence, visit http://creativecommons.org/licenses/by/4.0/.

\section{References}

Alsmith, A. J. (2017) Perspectival structure and agentive self-location. In de Vignemont, F., \& Alsmith, A. J. (Eds.). The Subject's Matter: Self-Consciousness and the Body (pp. 263-289). MIT Press.

Bermúdez, J. L. (1998). The paradox of self-consciousness. MIT Press.

Bermúdez, J. L. (2017). Understanding" I": Language and thought. Oxford University Press.

Binet, M. A. (1885). Vertigo of direction. Mind, 10(8), 156-159.

Binet, M. A. (1894). Reverse illusions of orientation. Psychological Review, 1(4), 337.

Brewer, B. (1992). Self-location and agency. Mind, 101(401), 17-34.

Bufacchi, R. J., \& Iannetti, G. D. (2016). Gravitational cues modulate the shape of defensive peripersonal space. Current Biology, 26(21), R1133-R1134.

Bufacchi, R. J., \& Iannetti, G. D. (2018). An action field theory of peripersonal space. Trends in cognitive sciences., 22(12), 1076-1090.

Burgess, N., Trinkler, I., King, J., Kennedy, A., \& Cipolotti, L. (2006). Impaired allocentric spatial memory underlying topographical disorientation. Reviews in the Neurosciences, 17(1-2), 239-252.

Campbell, J. (1995). Past, space, and self. MIT Press.

Cassam, Q. (1997). Self and world. Oxford: Oxford University Press.

Schwenkler, J. (2014). Vision, self-location, and the phenomenology of the "point of view.". Noûs, 48(1), $137-155$.

Cheung, A., Ball, D., Milford, M., Wyeth, G., \& Wiles, J. (2012). Maintaining a cognitive map in darkness: The need to fuse boundary knowledge with path integration. PLoS Computational Biology, 8(8), e1002651.

Cooper, H. S. (1976). A house in space. Holt, Rinehhart and Winston, Austin, TX.

De Monticelli, R. (1986). On orientation. Topoi, 5(2), 177-185.

Di Friedberg, M. S. (2017). Geographies of disorientation. Routledge.

Dreyfus, H. L. (1991). Being-in-the-world: A commentary on Heidegger's Being and Time, Division I (Vol. 1). Mit press.

Ekstrom, A. D., Huffman, D. J., \& Starrett, M. (2017). Interacting networks of brain regions underlie human spatial navigation: a review and novel synthesis of the literature. Journal of neurophysiology, 118(6), 3328-3344.

Evans, G. (1982). The varieties of reference Oxford University press Oxford.

Flournoy, T. (1893). Des phénomènes de synopsie (audition colorée): Photismes-schèmes visuelspersonnifications. Paris: Félix Alcan.

Fuchs, T. (2005). The phenomenology of body, space and time in depression. Comprendre, 15, 108-121.

Graziano, M. S., \& Cooke, D. F. (2005). Parieto- frontal interactions, personal space, and defensive behavior. Neuropsychologia, 44, 845-859.

Heidegger, M (1962). Being and time, trans. Macquarrie, J, \& Robinson, E. SCM Press, London.

Husserl, E. (1970). The crisis of European sciences and transcendental phenomenology: An introduction to phenomenological philosophy. Northwestern University Press.

Husserl, E. (1990). Ideas pertaining to a pure phenomenology and to a phenomenological philosophy: Second book studies in the phenomenology of constitution (Vol. 3). Springer Science \& Business Media.

Husserl, E. (2012a). Analyses concerning passive and active synthesis: Lectures on transcendental logic (Vol. 9). Springer Science \& Business Media.

Husserl, E. (2012b). Ideas: General introduction to pure phenomenology. Routledge.

Johnston, R. S., \& Dietlein, L. F. (1977). Biomedical results from Skylab. NASA SP-377. In Biomedical Results from Skylab (Vol. 377). 
Kant, I. (1786). What does it mean to orient oneself in thinking? In I. Kant (Author) \& A. Wood \& G. Di Giovanni (Eds.) (1996)., Religion and Rational Theology (The Cambridge Edition of the Works of Immanuel Kant, pp. 1-18). Cambridge: Cambridge University Press. https://doi.org/10.1017 /CBO9780511814433.003.

Klatzky, R. L. (1998). Allocentric and egocentric spatial representations: Definitions, distinctions, and interconnections, In Spatial cognition (pp. 1-17). Berlin: Springer.

Moran, D., \& Cohen, J. (2012). The Husserl dictionary. Bloomsbury Publishing.

Millière, R. (2019). Are there degrees of self-consciousness? Journal of Consciousness Studies, 26(3-4), 252282 .

Oman, C. (2007). Spatial orientation and navigation in microgravity. In Spatial processing in navigation, imagery and perception (pp. 209-247). Springer, Boston, MA.

Oman, C. M. (1987). The role of static visual orientation cues in the etiology of space motion sickness. In Proceedings of the symposium on vestibular organs and altered force environment (pp. 25-37).

Oman, C. M. (1990). Symptoms and signs of space motion sickness on Spacelab-1. Motion space sickness, 217-246.

Oman, C. M., Lichtenberg, B. K., Money, K. E., \& McCoy, R. K. (1986). MIT/Canadian vestibular experiments on the Spacelab-1 mission: 4. Space motion sickness: Symptoms, stimuli, and predictability. Experimental Brain Research, 64(2), 316-334.

Peacocke, C. (2019). The primacy of metaphysics. Oxford University Press.

Sartre, J. P. (1956). Being and nothingness, trans. Hazel E. Barnes. Philosophical library, New York, 308.

Schellenberg, S. (2007). Action and self-location in perception. Mind, 116(463), 603-632.

Solnit, R. (2005). A field guide to getting lost. London: Viking.

Straus, E. W. (1966). Phenomenological psychology: The selected papers of Erwin W. Straus. Londres: Tavistock Publications.

Waller, D., \& Hodgson, E. (2006). Transient and enduring spatial representations under disorientation and selfrotation. Journal of Experimental Psychology: Learning, Memory, and Cognition, 32(4), 867.

Wang, R. F., \& Spelke, E. S. (2000). Updating egocentric representations in human navigation. Cognition, 77(3), 215-250.

Publisher's note Springer Nature remains neutral with regard to jurisdictional claims in published maps and institutional affiliations. 